\title{
O Ensino Religioso para ensinar ou formar? Um tema forte e delicado
}

\author{
The Religious Education for teach or train? \\ A strong and delicate theme
}

\section{Eulálio Figueira}

Professor do Departamento de Ciência da Religião da Pontifícia Universidade Católica de São Paulo (PUC-SP), coordenador de Especialização em Ciências da Religião da PUC-SP, São Paulo, SP - Brasil, e-mail: eapfigueira@gmail.com

\section{Resumo}

Tratar da temática do que deve ser ensinado dentro de uma sala de aula, sabendo que não se trata de um ato gratuito e muito menos sem repercussões, constitui tarefa bastante árdua, pois isso envolve a definição dos rumos que a humanidade irá tomar. Cada conteúdo e cada metodologia levada para dentro de uma sala de aula não têm o mesmo impacto que uma conversa de bar. Uma disciplina curricular introduzida na regularidade das salas de aula deve ter como objetivo produzir um leque mais alargado de testemunhos. Deverá tomar como objeto de seu trabalho a experiência religiosa. Desse modo, entende-se que o estudo resultante dos esforços do Ensino Religioso pode ajudar, de modo relevante, não só a compreender, mas a identificar o pensamento religioso 
da geração contemporânea, ou dito de outro modo: ajudar a perceber como homens e mulheres, em seus lugares hodiernos, produzem razões para fazerem o que fazem e como fazem.

Palavras-chave: Ensino Religioso. Sala de aula. Experiência religiosa.

\section{Abstract}

Addressing the issue of what should be taught in a classroom, knowing that this is not a gratuitous act, much less with no repercussions, it is too hard, because it is defining the directions that mankind will take. Each and every content methodology brought into a classroom does not have the same impact as a conversation in a bar. Discipline curriculum introduced in the regular classrooms of our schools should aim to produce a wider range of evidence and should take religious experience as the object of its work. Thus I consider that the study resultant of the efforts of the Religious Education can help, in a relevant way, not only to understand but to identify the religious thought of the contemporary generation, or in other words: help us to understand how men and women produce reasons for doing what they do and how they do.

Keywords: Religious Education. Classroom. Religious experience.

\section{Introdução}

Se trata de duvidar da miséria humana - do domínio que as coisas e os maus exercem sobre o homem [...]. Mas ser homem é saber que é assim. A liberdade consiste em saber que a liberdade está em perigo. Mas saber ou ter consciência é ter tempo para evitar e prevenir o momento da inumanidade (LEVINAS, 1980).

Tratar da temática do que deve ser ensinado dentro de uma sala de aula, sabendo que não se trata de um ato gratuito e muito menos sem repercussões, constitui tarefa bastante árdua, pois estão sendo os definidos rumos que a humanidade irá tomar. Cada conteúdo e cada metodologia levada 
para dentro de uma sala de aula não têm o mesmo impacto que uma conversa de bar. Quem não já ouviu, ou até disse: minha professora, meu professor disse tal coisa? Na escola aprendi ou li tal coisa? Isto ou isso eu aprendi na escola? Em nossa cultura, a sala de aula cada vez mais se apresenta como o espaço onde, consideravelmente, passamos o maior período de nossas vidas, onde recebemos boa parte das informações e orientações que fazem nossas escolhas e monitoram nossas decisões - presentes e futuras. Mesmo que se tenham todas as justificativas sobre a necessidade de que semelhante tarefa se põe como constitutiva e constituinte de nossa era e de nossa sociedade, ainda assim a temática do debate acerca do que ensinar e para que se ensinar afigura-se como um desafio impar para os educadores. Não podemos esquecer que o debate sobre o educar e sobre o ensinar passa pelo debate sobre a existência humana e passa pela discussão acerca, como diz Levinas, da inumanidade.

Atualmente se assiste com uma frequência cada vez maior e mais barulhenta aos descasos e até menosprezos das práticas e conhecimentos com que grupos humanos e sociedades têm, por vezes, produzido e elaborado razões para se dizerem seres vivos e seres vivos humanos, passando como rolo compressor por cima das práticas e dos conhecimentos daqueles que não possuam algum instrumento de força de comunicação ou de poder político econômico. Não se quer aqui cair em falsos moralismos, mas também não se pretende adubar o relativismo e muito menos o permissivismo, dando asas ao falso argumento de que tudo deve ser olhado em função das liberdades e culturas dos povos. Também não é possível aceitar que, em nome da defesa do desenvolvimentismo e do progresso, infiltrem-se nos espíritos das culturas mudanças e transformações que em nada contribuem para a valorização e garantias de seus domínios.

Tem sido rotineiro, pelo mundo afora, a desvalorização e desconsideração dos argumentos apresentados por grupos humanos, bem como de suas respostas face à produção da vida, tipificando-as como representantes de tempos passados ou como coisa de não humano. Ainda há quem ache que índio pode ser queimado nas ruas de nossas cidades porque não é reconhecido como gente, ou então diante da pressão de alguns grupos transfere-se a não humanidade ou inumanidade para outra figura bastante comum em nossas cidades: o morador de rua ou o mendigo, tomando-os em definitivo como não gente, porque não são reconhecidos em seus espaços, seus territórios e suas expressões, e assim devem, sob o 
auspício da limpeza, ser eliminados dos espaços que ocupam - pois além de ocuparem um espaço, sua ocupação é feita de forma desordenada, feia e fétida. Isso defendem alguns.

Alguns ainda ensaiam algumas reações a esse tipo de comportamento de expulsão e de extermínio moderno, no entanto são muitas vezes engolidos pela força dos argumentos da dignidade humana, pela força dos argumentos fundados no cinismo moral e social. Assim, aqueles que ainda seriam capazes de reconhecer que nos grupos e sociedades diferentes - porque não têm conta bancária, não usam celular ou não assistem ao Big Brother - há sem dúvida valores e razões para viverem como vivem, rapidamente tratam de descaracterizar a possível força do argumento diante do "valoroso" em prol do desenvolvimento, do progresso e da modernidade, procurando até aproximar aquele modelo de uma certa primitividade ou, numa conotação mais branda, de uma certa exoticidade - para fugirmos do peso que o termo primitivo possa carregar - e assim, slogans do tipo "solidariedade, compaixão, cidadania" ficam circunscritos ao sinônimo da ideia: "sou solidário com aqueles que não entopem meu caminho, sou cidadão com aqueles que vivem na minha cidade". Mas o que faz uma cidade? O que constitui a dignidade humana?

\section{Ensino Religioso, uma opção ou uma decisão?}

Para atacar de imediato o problema da religião na sala de aula, este artigo propõe que a questão seja enfrentada com a pergunta: o que a religião tem a dizer sobre os possíveis rumos da humanidade e das relações que esta estabelece? É a religião componente fundamental para a constituição do que se denomina humano? Se dermos uma rápida percorrida pelos documentos - leis, diretrizes, ensinamentos, instruções, etc. - que tanto governos como entidades religiosas têm produzido, observamos que o Ensino Religioso Escolar, principalmente nos últimos anos, é posto como um componente fundamental no sistema educacional. Justificativas para tal vão desde o reconhecimento que o Ensino Religioso encampa e garante a liberdade de escolha diante do gênero de educação que os pais pretendem para seus filhos, a garantia de assegurar uma educação religiosa e moral, como ainda a garantia de uma educação integral da pessoa, de forma que a tônica do pleno desenvolvimento da personalidade humana e do sentido da sua 
dignidade, reforçando o respeito pelos direitos humanos e pelas liberdades fundamentais, facilite a formação da cidadania, preparando o educando para uma reflexão consciente sobre os valores espirituais, estéticos, morais e cívicos.

Observa-se que o reforço posto nos documentos que apontam a presença do Ensino Religioso no sistema de ensino está alinhado com a ideia e princípio de que a educação integral da pessoa humana passa efetivamente pela educação moral e religiosa, dado que o enquadramento moral e religioso da vida é estruturante para o crescimento de crianças e jovens. O desenvolvimento pleno das crianças e dos jovens constitui um universo de referência a partir do qual se estrutura a personalidade e se adquire uma visão do mundo equilibrada e aberta ao diálogo com mundividências alternativas.

O mundo atual, composto não somente de uma pluralidade de fatores, mas também de uma diversidade destes fatores - tensões múltiplas, contradições, avanços e recuos -, só poderá ser compreendido em sua complexidade na medida em que soubermos entender os fatos religiosos, e para tal é necessário o domínio no campo do conhecimento religioso. Crianças e jovens necessitam de um conhecimento sério do fenômeno religioso para não só compreender o mundo, mas para sobre ele poder agir. Tal conhecimento dará a esses jovens e crianças condições para conhecer suas potencialidades conflituais - tantas vezes exploradas por fanatismos radicais -, mas, acima de tudo, suas possibilidades de promover e facilitar a construção de relações fundadas no entendimento e no encontro entre todos os seres humanos. Como diz Hans Kung (1993, p. 7), não haverá paz entre as civilizações sem paz entre as religiões, nem paz entre as religiões sem diálogo entre as religiões. É efetivamente esse diálogo, possibilidade peculiar dos humanos, que nos fará cuidadores da vida e do mundo. A possibilidade da paz estará na medida em que as futuras gerações conseguirem e se esforçarem por compreender mais os eventos de cada sociedade. Certamente não será possível compreender muitos dos eventos internacionais sem uma clara referência ao religioso e às suas múltiplas manifestações.

O Ensino Religioso deve ser uma disciplina integrada na grade curricular dos sistemas de ensino e deve funcionar não somente com um caráter facultativo - caso o fosse, então não faria sentido dizer que ela é determinante na educação integral -, mas como disciplina que se integre ao núcleo das demais, que têm como objetivos fundamentais educar - e não apenas formar - para a dimensão moral e religiosa e, acima de tudo, para o 
que é mais peculiar de sua matriz educacional: a compreensão dos elementos mais profundos da cultura nacional, necessariamente aberta ao mundo.

A carta circular da Congregação para a Educação Católica, enviada aos presidentes das Conferências Episcopais sobre o Ensino da Religião na Escola, assinala algumas instruções e princípios que julgo importantes para demonstrar a pertinência e o acento do Ensino Religioso no currículo escolar e sua componente. Diz a carta:

a educação apresenta-se como uma tarefa complexa, desafiada pelas rápidas mudanças sociais, econômicas e culturais. A sua missão específica permanece a formação integral da pessoa. Às crianças e aos jovens deve ser garantida a possibilidade de desenvolver harmoniosamente as próprias qualidades físicas, morais, intelectuais e espirituais. Os mesmos devem ser ajudados a adquirir um sentido mais perfeito da responsabilidade, a aprender o reto uso da liberdade e a participar ativamente da vida social. Um ensino que desconhecesse ou marginalizasse a dimensão moral e religiosa da pessoa constituiria um obstáculo para uma educação completa (CARTA CIRCULAR, 2009).

A educação é tarefa que precisa ser assumida por educadores. Educar não pode ser traduzido por formar, pois educar é mais do que definir regras de comportamento, é possibilitar a capacidade de assumir decisões. Nisso reside a complexidade que a educação assume hoje. Desse modo, não cabe entender que o Ensino Religioso assuma um caráter confessional, em que uma determinada instituição religiosa ou Igreja determine o que se deva ensinar dentro da sala de aula. É importante que as Igrejas ou instituições religiosas tenham sua liberdade para catequizar, ensinar e promover suas doutrinas, manifestar seus rituais, etc., mas educação, como modo de conhecimento, se faz seguindo outras dinâmicas. O caráter confessional das religiões compete às religiões, mas a religião também se reveste de um caráter público, e este deve ficar fora delas.

\section{Religião: coisa pública ou coisa privada?}

Penso que a grande dificuldade para enfrentar tais questões deve-se ao fato de tradicionalmente ter-se fundamentado a ideia de uma dignidade humana como resultado de uma essencialidade humana, de ter- 
se acreditado que existe ou existirá uma natureza além da história capaz de apresentar uma idealidade do homem, algo como uma supra-humanidade, capaz de levar os homens e mulheres de cada época, vivência e experiência a comportamentos exímios que se perpetuem. Seria a humanidade capaz de produzir ações e premissas possíveis de identificar o que se deve tomar como justo ou injusto, isto é, seguindo o pensamento de Rorty (1992, p. 235), e não cair em argumentos que façam recair sobre os nossos ombros o que nos pode levar à crueldade?

A maneira filosófica tradicional de explicar aquilo que entendemos por solidariedade humana é dizer que há algo dentro de cada um de nós - a nossa humanidade essencial - que ressoa como a presença dessa mesma coisa em outros seres humanos.

Sair dessas armadilhas será possível quando percebermos a dimensão de nossa contingência de forma a reconhecer que devemos nos opor a ideias como a da essencialidade humana, como diz Rorty, um "eu central", uma "natureza" e um "fundamento". Só esse reconhecimento permite que nos afastemos das afirmações de que há algumas ações e atitudes que são naturalmente "desumanas". Defendemos, tal como Rorty (1992, p. 235), que

esta insistência (na contingência) implica que aquilo que conta como sendo um ser humano decente seja relativo às circunstâncias históricas, seja questão de um consenso passageiro quanto a saber que atitudes são normais e que práticas são justas ou injustas.

É importante perceber os momentos nos quais as sociedades, em seus processos históricos, passam por crises, reconhecer quando a história entra em convulsão e, como resultado de tudo isto, as instituições, organismos criados por homens e para os homens, entram em ruptura com padrões de comportamentos tradicionalmente tomados como desejáveis. Esses momentos históricos devem ser vistos em sua contingencialidade e não atribuídos a uma essencialidade, a um fundamento criado na teoria das ideias inatas, segundo as quais as pessoas nascem com ideias matemáticas, verdades eternas e noção de Deus, capazes de nos fazer chegar às verdades manifestas. Os homens e as mulheres fazem o que fazem e assumem como justo ou injustos seus comportamentos ou os comportamentos alheios porque, tal 
como Kant o havia proposto, seguem uma ordem Moral já impressa em sua essencialidade, isto é, instalada em um sistema de moralidade que se funda na perspectiva segundo a qual a ideia de uma componente humana central e universal se resume na Razão, que, por sua vez, apresenta-se como uma faculdade que seria a fonte das nossas obrigações morais. Não parece ser o que devemos buscar construir como razoabilidade para o fazer humano. Contudo, como diz Rorty, não se nega que se deva procurar uma saída diante desses momentos de convulsão e de ruptura, pois "queremos algo que se encontre para lá da história e das instituições. E que poderá haver, a não ser a solidariedade humana, o nosso conhecimento da humanidade de outrem que nos é comum?" (RORTY, 1992, p. 236).

Pois a saída então não é buscar construir referências em fundamentos que não podem responder a nossos efetivos problemas, mas também não podemos ficar na impossibilidade do agir, presos a desculpas céticas. Se não devemos confiar no que esteja para lá da história e das instituições como nos ensina Rorty -, devemos produzir utopias, mas utopias que nos possibilitem reconhecer nossas humanidades:

uma crença pode continuar a reger a ação, pode-se continuar a considerar que vale a pena morrer por ela, mesmo entre pessoas que estão plenamente conscientes de que essa crença não é causada por nada de mais profundo do que as circunstâncias históricas (RORTY, 1992, p. 236).

Não entendemos que a justificativa de uma disciplina do Ensino religioso se faça em meio a argumentos como: porque nos ensinará a ser mais responsáveis, mais cidadãos ou mais respeitadores das ordens morais. Entendemos que uma disciplina como o Ensino Religioso nos poderá construir sujeitos históricos melhor sabedores de seus recursos, mais conhecedores das possibilidades e capazes de entender mais os fatos em nosso redor. O Ensino Religioso nos ajudará a construir o que Rorty aponta como a Utopia liberal. Isto é, a Solidariedade Humana. Essa solidariedade que Rorty propõe não é pensada como sendo

reconhecimento de um Eu Central, da essência humana em todos os seres humanos. É antes pensada como sendo a capacidade de ver cada vez mais diferenças tradicionais (de tribo, religião, raça, costumes, etc.) como não importantes, em comparação com 
semelhanças no que respeita à dor e à humilhação - a capacidade de pensar em pessoas muito diferentes de nós como estando incluídas na esfera do nós (RORTY, 1992, p. 239).

Voltando ao foco do problema: o que se deve ensinar dentro de uma sala de aula? E o que se ensina de importante para que alguém se torne suficientemente capaz para viver na sociedade, ou nas sociedades de nosso tempo? A pergunta inicial nos remete para uma segunda discussão, não menos desafiante e delicada que a que acabamos de colocar, a saber: é possível formar alguém? O que significa formar alguém? Claro que esse teor nos leva para a discussão positivista sobre a natureza humana, que já foi falada tanto por Hobbes, Locke e Rousseau, como por tantos outros seus discípulos, mas acho que é necessário retomar o debate, desde que se avance às lacunas deixadas pelo reducionismo tanto criacionista, como darwinista.

\section{Eu estou aqui, homens de pouca fé}

Tem a religião algo a nos dizer? Em que ela nos pode convencer de modo a permitirmos que ela nos sussurre algumas palavras de: eu estou aqui?

Proponho que, de forma direta e sem mais rodeios, apresente-se a religião, isto éa "distinta senhora" alvo de nossa contenda neste ensaio. Afinal, por que e para que trazer a religião para dentro da sala de aula? Faço, desde já, uma confissão de argumento: nossa proposta não é um argumento metodológico, e sim uma proposta pragmática. Trata-se de assumir o debate sobre o foco da pertinência do estudo sobre o objeto - na medida em que ele reclama um estudo -, e não de como o estudo será feito, isto é, que conhecimento se faz necessário de modo que a religião seja observada, perscrutada e analisada de dentro dela, sem que se caia nas garras do reducionismo ou, no que não seria menos danoso, nas garras do fundacionismo. A justificativa para o estudo da religião na sala de aula deve ser construída no princípio do que alguém pode atingir com tais estudos. Proponho uma pergunta para orientar nosso argumento: por que um pai pediria que, na escola em que matriculou seu filho, este viesse a ter aula de religião? Será que o mesmo argumento se daria como justificativa para explicar por que o ensino da religião não pode ficar de fora do currículo da escola? 
Proponho então que seja formulada a seguinte pergunta a todos os pais que buscam uma escola que tenha em suas norma curriculares o ensino da religião: por que o senhor pede o ensino da religião para seu filho? O senhor está pondo o seu filho na escola que oferece o estudo da religião por que essa escola se apresenta diferente em quê, daquela que não oferece tal estudo?

Tratar da religião na sala de aula significa enfrentar as grandes questões que afetam a forma como homens e mulheres constroem suas razões efetivas para viver como vivem e por que vivem, na nossa sociedade. Discutir religião já nas séries iniciais da educação formal significa assumir a necessidade de perceber que a vida não está posta somente na necessidade de construir modos de coesão social, muito menos de se reduzir à luta pela sobrevivência, pois viver e morrer não se fixa na discussão sobre quando um corpo para de funcionar. Diante da necessidade da coesão social, como diz Rorty, a ciência natural e o senso comum da modernidade o fazem com competência, mas se pensamos que viver é algo mais, algo que se coloca mais além - e este além não se trata de um mundo metafísico, mas de construir proposta de solidariedade -, então um conhecimento religioso pode mostrar-se não apenas necessário, mas vantajoso. Nesse conjunto de ideias, significa tratar de colocar a religião fora de uma referência a um mundo metafísico, falar da religião fora da metafísica, apresentar a religião no registro da interpretação, da hermenêutica e do pragmatismo, como possibilidade de se produzir sobre o mundo uma interpretação e não uma inteligibilidade.

O debate da religião e os estudos dela e sobre ela, na sala de aula, nos levarão a mapear os caminhos que constroem a inumanidade - como dizia Lavinas -, ou, no dizer de Rorty, o que nos fazem mais cruéis. Assim, religião não é para que nos tornemos mais dignos, mas menos inumanos ou menos cruéis, pois por ela perceberemos nossas contingências, o que nos afastará de considerar que algumas afirmações serão mais humanas do que outras. O estudo da religião deve abrir para a discussão sobre as práticas de que discriminação étnica e religiosa é tratar de identidade, autonomia, alteridade, valores, tradições, símbolos, indivíduos, coletividades, singularidades, pluralidades. É tratar também de fronteiras, relações intra e intergrupos, inclusões, exclusões.

O ensino de religião não deve existir para formar cidadãos nem mais conscientes, nem mais responsáveis. Tratar da religião na sala de aula 
significa enfrentar as grandes questões que afetam a forma como homens e mulheres, na nossa sociedade, constroem suas razões efetivas para viver como vivem e porque vivem. Discutir religião já nas séries iniciais da educação formal é assumir a necessidade de perceber que a vida não está posta somente no imperativo de construir modos de coesão social. E, desta feita, a religião deve ser posta diante dos horizontes dos que pensam a vida em sociedade e organizam as relações que engendram esta forma de vida humana, como não apenas um conjunto de crenças, ou até mesmo um sistema que apenas justifica as organizações sociais. Religião deve ser lida e percebida como justificativa humana diante da necessidade de resposta a três grandes inquietações: injustiça, ignorância e sofrimento.

Religião reclama ser estudada e compreendida como uma produção de homens e mulheres que buscam respostas e modos de justificarem a si, ao mundo e no mundo. Por isso, é preciso instrumento cognitivo capaz de captar esses sinais constitutivos do fato religioso. Faz-se necessário elaborar discurso que, mantendo a peculiaridade da religião, transite da mesma forma pela "vereda" do discurso científico.

\section{A religião na esteira do discurso científico}

Para se pensar uma epistemologia da Ciência da Religião, é forçoso colocar os estudos no terreno do conhecimento, o que significa levantar a pergunta: o que faz com que algo de verificável possa ser dito sobre o religioso? Reconhecemos que, hoje, a discussão deve ser levada definitivamente e com coragem para uma nova fronteira, a fronteira do epistêmico. Trazer a religião para o "palco" do conhecimento e apontar que epistemologia se torna constitutiva e capaz de conferir à Ciência da Religião identidade de ciência implica colocar a interrogação: que conhecimento se constitui capaz de dar pertinência epistemológica a esta disciplina? O que, por sua vez, coloca em discussão também a questão sobre o que se pode conhecer. Nesse percurso, cabe também perguntar que epistemologia poderá servir à Ciência da Religião, de modo a proporcionar-lhe a possibilidade de um trabalho científico nessa área.

Constatamos que os estudos sobre o fato religioso têm recebido atenção por parte de várias disciplinas que se ocupam das "inquietações" e expressões humanas. A presença da religião nessas disciplinas, no espaço da 
academia e nos círculos constituídos por pensadores que, há algumas décadas, vêm colocando a discussão e reclamando o direito de reconhecimento desta no lugar de ciência, não se questiona mais. Dito de outro modo, a religião e seu estudo têm seu lugar na academia e nos círculos de estudo de pesquisadores e estudiosos, não necessitando mais, como em outros tempos, de justificativa ou pedido de licença para sua presença nesses círculos. Já perdeu relevância a simples e "surrada" argumentação de que a religião é um objeto neutro, e que já existem muitas abordagens que se debruçam sobre ela, não havendo necessidade de mais uma disciplina. Também se esgotou o argumento de que a religião trata de uma ordem de coisas que estão no estrato intimista do ser humano e que, por essa razão, não poderá haver uma disciplina de caráter científico que dela possa se ocupar.

É preciso assumir-se os estudos do fato religioso, que propomos como Ciência da Religião, uma disciplina acadêmica que se distingue da teologia e da catequese, não sendo, por tal razão, corretamente empreendida para promover ou impulsionar qualquer tipo específico de crença religiosa. Deverá este estudo oferecer-nos visão menos restrita e menos provinciana da religião, em específico daquela religião na qual fomos educados - e aqui entendemos não apenas os religiosos assim entendidos, mas também aqueles que foram educados como humanistas, ou ateus.

\section{Um estudo além de teístas e ateístas}

Parece-me deveras interessante trabalhar o debate acerca da manutenção ou da introdução ${ }^{1}$ de uma disciplina de estudos que leva na sua designação Ensino de Religião, Cultura Religiosa ou qualquer outro título que alude a abordar, desde uma compreensão interpretativa científica, a natureza e manifestação do fenômeno religioso, partir-se da linha de pensamento que Santiago Zabala desenvolve e expõe em sua Introdução ao debate realizado entre Rorty e Vattimo acerca da possibilidade do Futuro da Religião.

Por nos parecer ser este um trabalho de grande importância, passamos a analisar este material produzido no diálogo entre Rorty e Vattimo (2006), mediado por Santiago Zabala.

\footnotetext{
${ }^{1}$ Faço esta chamada para referir-me tanto aqueles casos em que a religião já é parte constituinte dos currículos das escolas, como aqueles em que tal fato é somente um desejo ou um projeto.
} 
Zabala indica, já nas palavras de John Dewey, um dos pais do neopragmatismo, a linha de condução de sua proposição para se abordar a natureza dos estudos sobre a religião:

quero desejar acima de tudo que o futuro da religião esteja ligado à possibilidade de desenvolver uma fé nas possibilidades de experiência humana e na capacidade humana de estabelecer relações, o que há de criar um sentido vital da solidariedade dos interesses humanos e de inspirar ações capazes de transformar este sentido em realidade (RORTY; VATTTMO, 2006, p. 19).

Significa partir do princípio de que a religião, como objeto de estudo, compreende-se como manifestação humana, na medida em que expressa um modelo de experiência humana e faz parte da capacidade humana de construir relações - relações essas que garantem poder se afirmar que a vida faz sentido. Podemos estão responder, ou, se assim não nos for possível, pelo menos dizer que se faz compreensível alguém dizer ter uma religião e que por ela orienta sua vida. Mais, é nela que ele (o crente) expressa suas mais profundas convicções de que vale a pena viver e que este viver tem um sentido. Religião não se fixa apenas em uma ilusão - assumindo a ideia de ilusão no seu sentido mais originário, como Nietzsche a cunhou -, mas ela ganha, na vida e nas relações que o fiel seguidor e praticante produz, sentido e praticidade, apresentando-se então como uma fonte não apenas de projeção, mas também de justificação do seu cotidiano e de suas ações.

Cabe ressaltar que, em Dewey, realidade não é assumida como a velha (clássica terminologia grega) oposição à aparência, mas as práticas concretas dos indivíduos, que devem ser percebidas como mutáveis e até distintas entre os vários indivíduos.

Nessa perspectiva, Rorty e Vattimo (2006) podem ser vistos como os esteios do novo iluminismo capaz de fugir às garras do objetivismo das Ciências Humanas, bem como ao conceito de cultura pelo qual os seres humanos já estariam como que predispostos a realizar o que realizam por determinação de uma ordem universal que lhes fosse superior e ulterior, sem que para isso ocorresse qualquer interesse ou funcionalidade. Se há nos seres humanos algum interesse em se adequar uns aos outros, isso se faz simplesmente pelo interesse em que tal aconteça e não porque haja uma determinação de algo que seja ulterior a essa praticidade.

É nesse "caldo" de ideias que Zabala introduz aquilo que entendemos vir a ser o mote do debate da religião em nosso tempo e em 
nossas sociedades cosmopolitas. Sem dúvida, o grande tema que nutre toda a conversa em religião nos círculos humanos de nossa sociedade é o problema acerca da existência de Deus e de como esta assume presença nas relações humanas. Significa assumir que a existência de Deus tem um peso na história da humanidade, pelo menos na história da humanidade que compõe nossa gênese cultural ocidental. O próprio gesto desconstrutivista da filosofia - veja-se o esforço da crítica religiosa, mesmo a mais radical, como a nietzschiana - não foi capaz de abolir o debate sobre Deus, então o melhor a se fazer é considerar esta existência com sua influência histórica - no entanto, esta presença deve ser observada dentro da devida postura ironista ${ }^{2}$.

Entendo e quero propor que uma disciplina curricular introduzida na regularidade das salas de aula de nossas escolas deve ter como objetivo produzir um leque mais alargado de testemunhos, ou como diz Rorty, maior número de audiências e algum entendimento sobre a evolução e as questões históricas, boas ou más, das várias formas de crença religiosas existentes no mundo. Deverá tomar como objeto de seu trabalho a experiência religiosa produzida pelos homens no intuito de interpretar o mundo. Desse modo, entendo que o estudo resultante dos esforços do Ensino Religioso pode ajudar, de modo relevante, não só a compreender, mas a identificar o pensamento religioso da geração contemporânea, ou, dito de outro modo, nos ajudar a perceber como homens e mulheres, em seus lugares hodiernos, produzem razões para fazerem o que fazem e como fazem.

A linguagem religiosa não é só um modo de explicar o mundo, visto que a ciência também o faz, mas é o modo, para o crente, de habitar o mundo. Nesse sentido, podemos dizer que a linguagem religiosa comunica a experiência do Sagrado sempre presente em todo o homem e de todas as idades. A experiência religiosa tem como finalidade a Transcendência. Nisso ela é uma experiência humana, portanto, própria do ser humano, aquele que busca a Transcendência. Assim religião, como experiência humana, é condicionada por sua forma de ser e pelo seu contexto histórico-cultural.

Derrida (2000), no livro A Religião pergunta-se como falar da religião e em particular da religião hoje e, mais ainda, como falar na religião no singular, sem ter medo de afirmar tratar-se de assunto antigo e novo ao mesmo tempo e mais, sem correr o risco de necessitar fazer algumas abstrações. Neste desafio Derrida (2000, p. 11-12) aposta que é necessário

\footnotetext{
${ }^{2}$ Ironia aqui assumida na noção empregada pelo velho mestre dos mestres, Sócrates.
} 
fazer algumas abstrações, apostar na mais concreta e na mais acessível, mas também a mais desértica das abstrações:

devemos nos salvar pela abstração ou nos salvar da abstração? Onde está a salvação? [...] Salvar, ser salvo, salvar-se. Pretexto para uma primeira pergunta: será que se pode dissociar um discurso sobre religião de um discurso sobre a salvação, isto é, sobre o são, o santo, o sagrado, o salvo, o indene, o imune? E a salvação será necessariamente a redenção diante ou depois do mal, da falta do pecado? Agora: onde está o mal?

A experiência religiosa surge nesse esforço humano de harmonia com o são, o santo. Por isso, essa relação exige ser pensada nos limites da simples razão. É preciso discernir, como bem o afirma Derrida (2000), que a fé nem sempre foi e nem sempre será identificável com a religião, tampouco com a teologia. Mais: nem toda a sacralidade e nem toda a santidade são necessariamente religiosas, no sentido estrito do termo, se é que existe um termo que possa dar conta de todo este problema. Mircea Eliade (1969), ao tratar da experiência religiosa, já alertava os estudiosos de seu tempo para o fato de não se encontrar um termo que fosse capaz de expressar tudo o que essa experiência congrega.

Portanto, os estudos acerca da religião e da experiência religiosa não podem ficar numa visão modalizante da relação sagrado/profano. A compreensão da religião não se encerra na antropologia. Religião não se define como um conjunto de representações que exprimem a natureza das coisas sagradas e as relações que estas produzem entre si e com as coisas profanas.

É necessário romper com a corrente ou correntes que lêem a relação sagrado/profano em termos do binômio religião/não religião. É importante compreender que a experiência religiosa, enquanto experiência humana, é relacional; portanto, é vivência relacional do crente com o mundo, com o outro e com o grupo humano, e nesta relação o homem religioso elabora sua experiência do sagrado.

A experiência religiosa é humana e, justamente por ser assim, sua relação com o sagrado é essencial, visto que o ser humano tende à totalidade e nesta totalidade está a salvação, salvação que se constitui na relevância da instância religiosa. Assim, a experiência religiosa é fundamentalmente centrar-se no tema da Salvação, entendida como libertar-se.

Salvação, observando-se a história, podemos dizer ser a componente específica em torno da qual todas as religiões giram. A possibilidade de se ser salvo constitui a grande marca de todas as religiões. Podemos então 
dizer que isso, a convergência da salvação, iguala a todas. Suas distinções se encontram não em seu destino, mas nos caminhos a serem percorridos. Podemos afirmar que todos somos filhos diferentes de deuses diferentes. Acredito que esse deve ser o tema central do Ensino Religioso, o fato de que homens e mulheres imersos em sua tarefa de produzir a vida, fazemno em bases sólidas de construir um sentido que justifica porque devemos ser menos cruéis. Não um sentido que se funda na essencialidade de um Mundo Melhor, mas na solidariedade de um Mundo Novo em oposição a um Mundo Velho. O Ensino Religioso deve ser a disciplina que seja capaz de oferecer às futuras gerações sementes de solidariedade que, como aponta Hans Kung (1993), apontem para uma paz criada no diálogo entre as religiões.

\section{Referências}

CARTA CIRCULAR DA CONGREGAÇÃO PARA A EDUCAÇÃO CATÓLICA. Carta Circular n. 520/2009. Disponível em: < http:/ / catolicosnarede.wordpress. com/2009/09/24/carta-circular-da-congregacao-para-a-educacao-catolica/>. Acesso em: 20 out. 2009.

DERRIDA, J. (Org.). A religião. São Paulo: Estação Liberdade, 2000.

ELIADE, M. Origens. Lisboa: Edições 70, 1969.

KUNG, H. Projeto de ética mundial: uma moral ecumênica em vista da sobrevivência humana. São Paulo: Paulinas, 1993.

LEVINAS, E. Totalidade e infinito. Tradução José Pinto Ribeiro. Lisboa: Edições 70, 1980.

RORTY, R. Contingência, ironia e solidariedade. Lisboa: Presença, 1992.

RORTY, R.; VATTIMO, G. O futuro da religião, solidariedade, caridade e ironia. Rio de Janeiro: Relume Dumará, 2006.

Recebido: 25/01/2010

Received: 01/25/2010

Aprovado: 08/03/2010

Approved: 03/08/2010 